\title{
Malaria-infected Mice are Cured by a Single Dose of Novel Artemisinin Derivatives
}

Gary H. Posner, $*{ }^{\mathrm{a}, \mathrm{b}}$ Ik-Hyeon Paik, ${ }^{\mathrm{a}}$ Wonsuk Chang, ${ }^{\mathrm{a}}$ Kristina Borstnik, ${ }^{\mathrm{a}}$ Sandra Sinishtaj, ${ }^{\mathrm{a}}$ Andrew S. Rosenthal, ${ }^{\mathrm{a}}$ and Theresa A. Shapiro ${ }^{\mathrm{b}, \mathrm{c}}$

${ }^{a}$ Department of Chemistry, School of Arts and Sciences, The Johns Hopkins University, Baltimore, Maryland

${ }^{\mathrm{b}}$ The Johns Hopkins Malaria Research Institute, Bloomberg School of Public Health 'Division of Clinical Pharmacology, Departments of Medicine and of Pharmacology and Molecular Sciences, School of Medicine

ghp@jhu.edu

\section{Supporting Information}

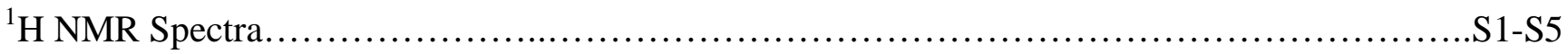

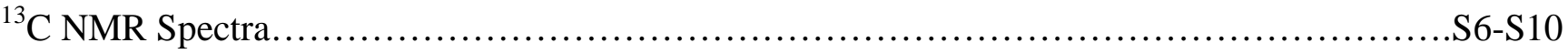

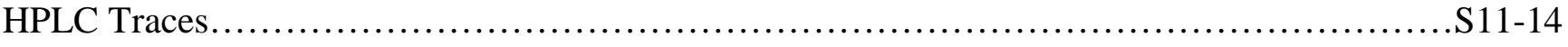



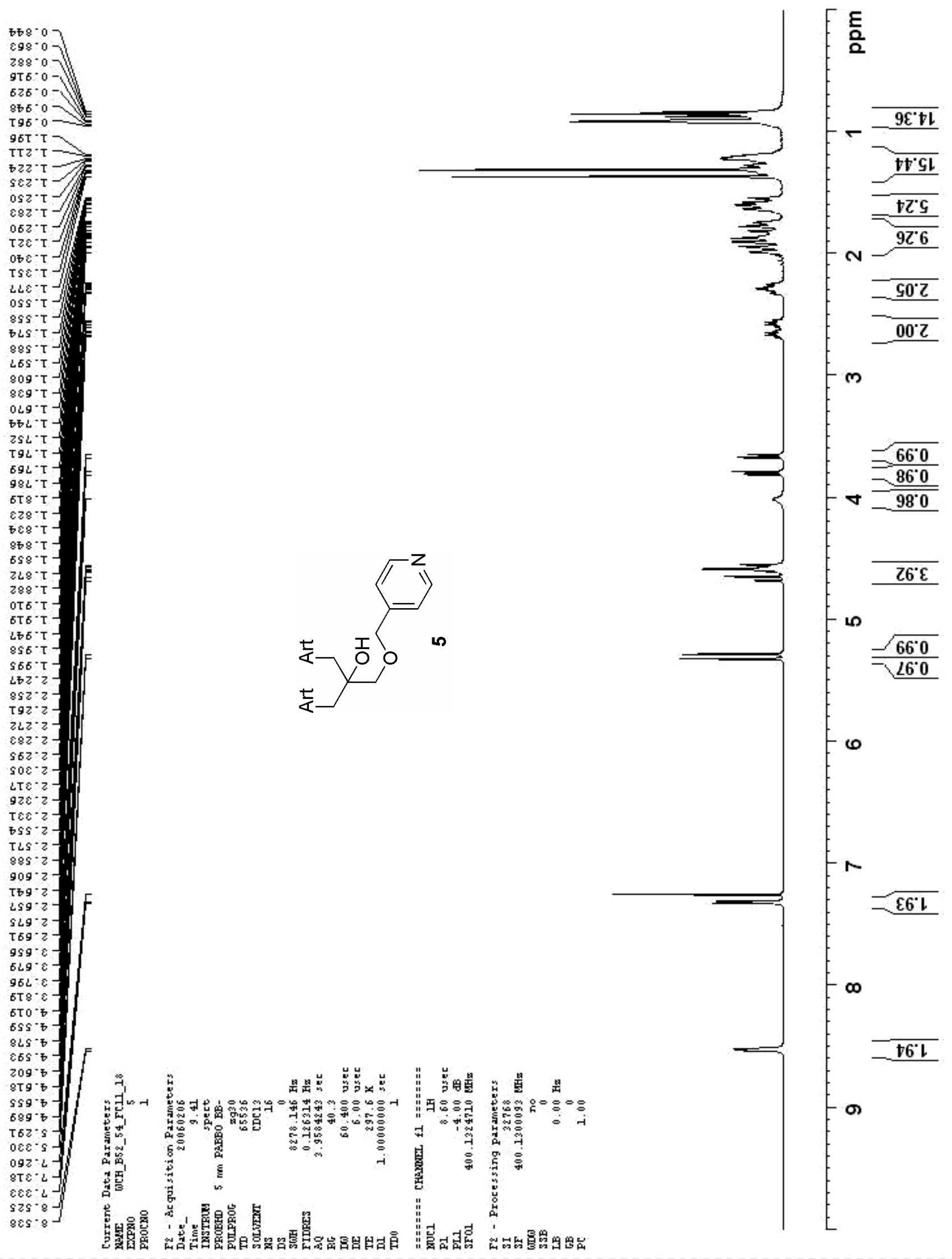

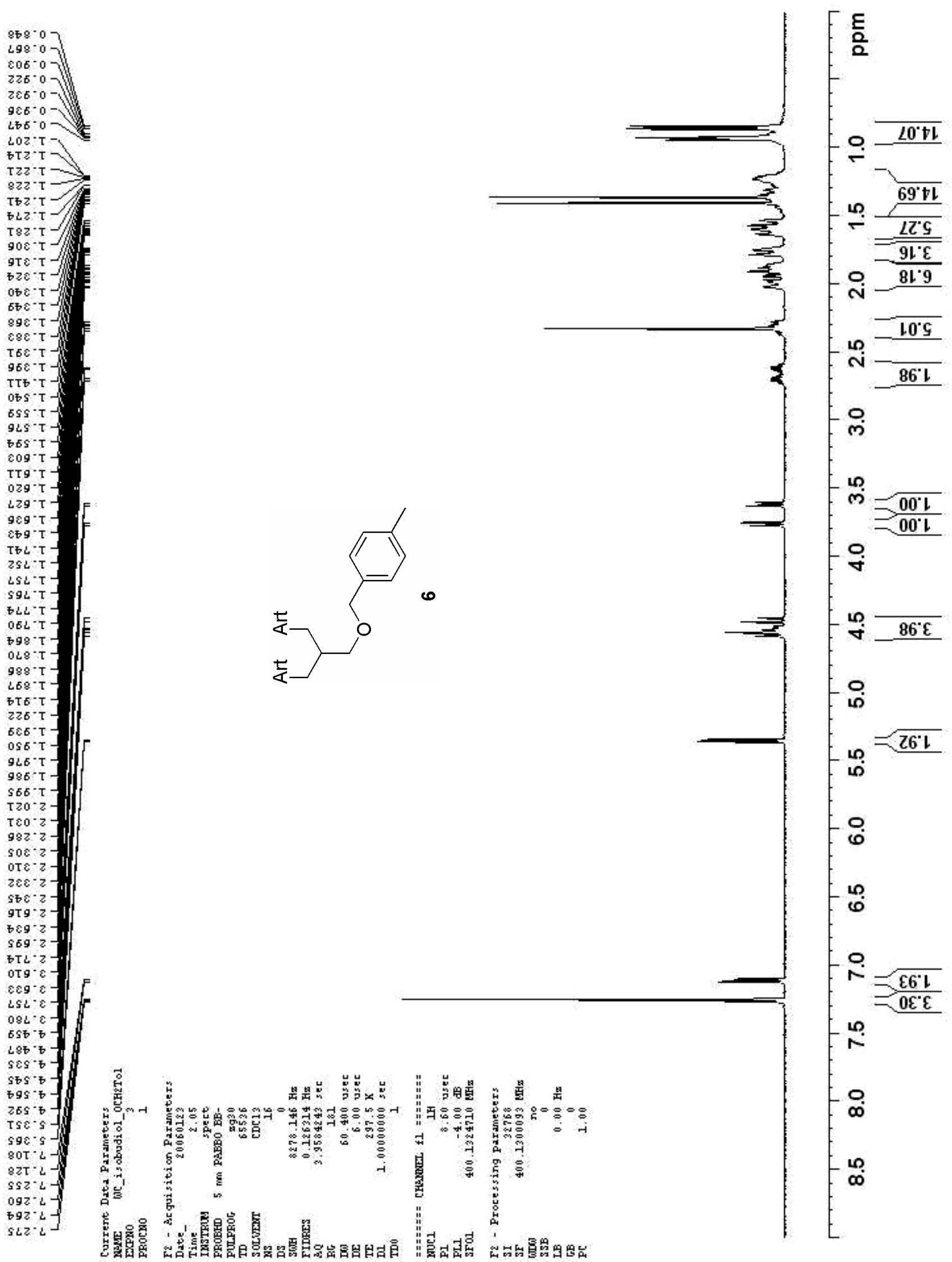


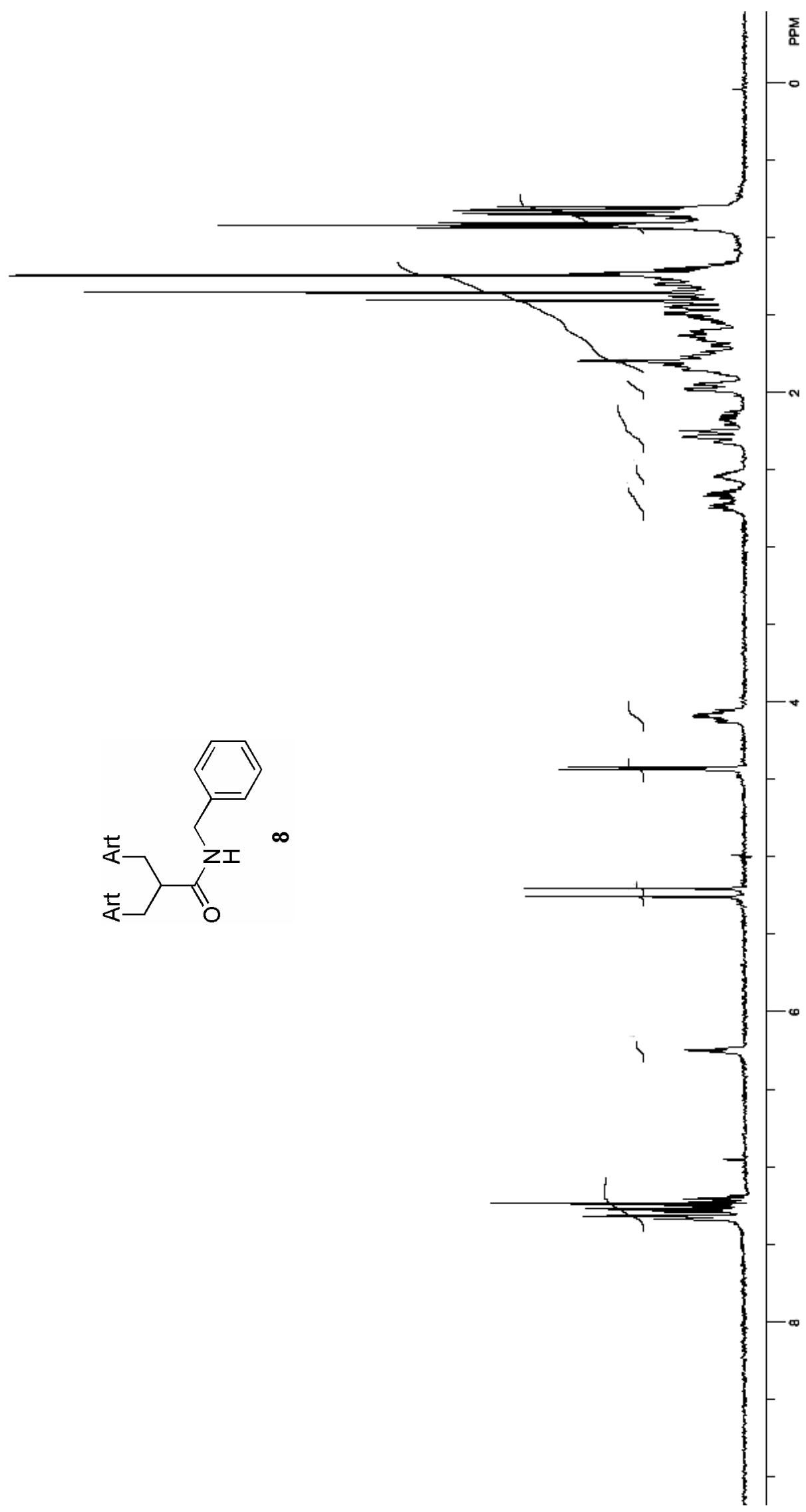




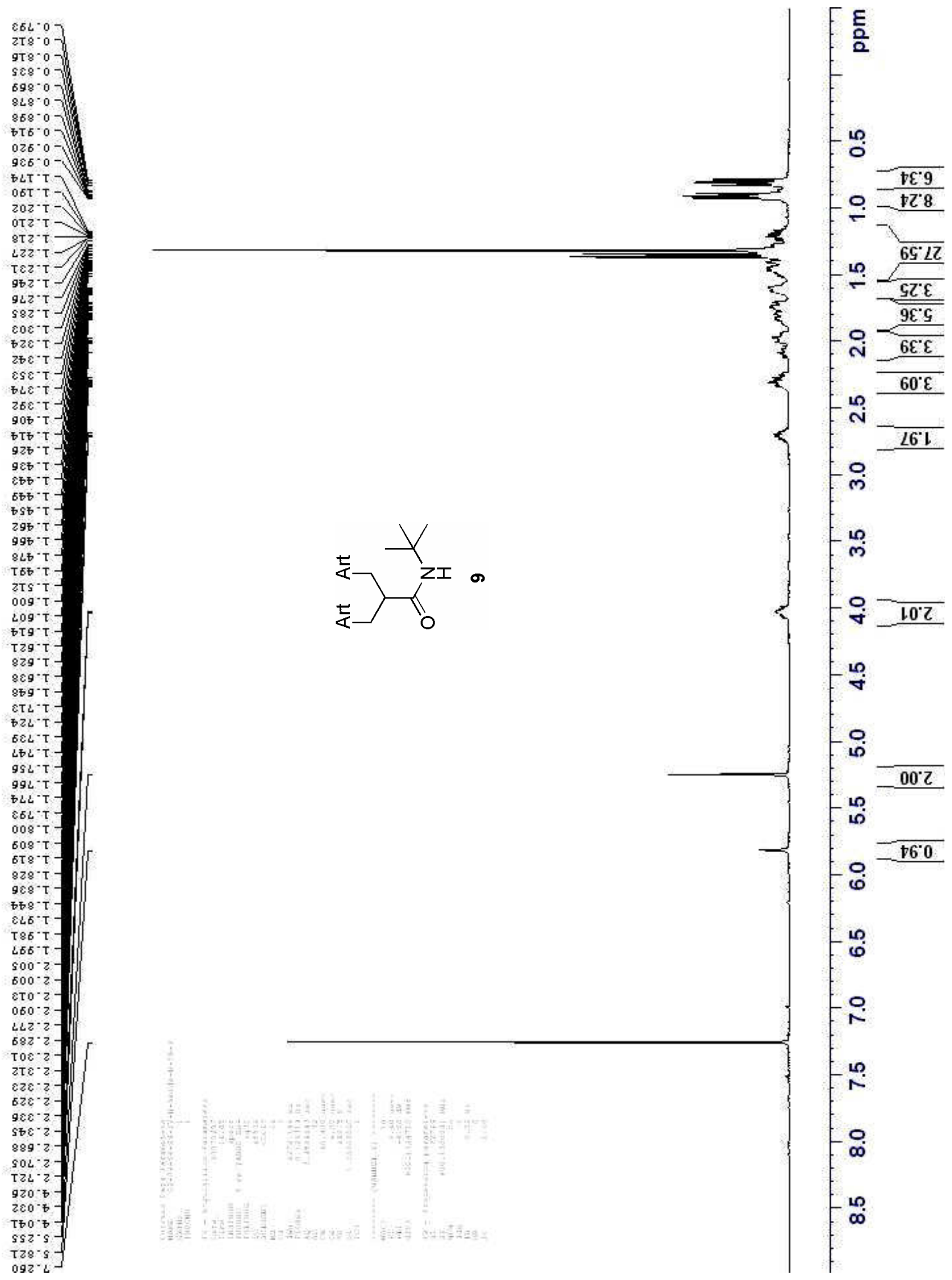




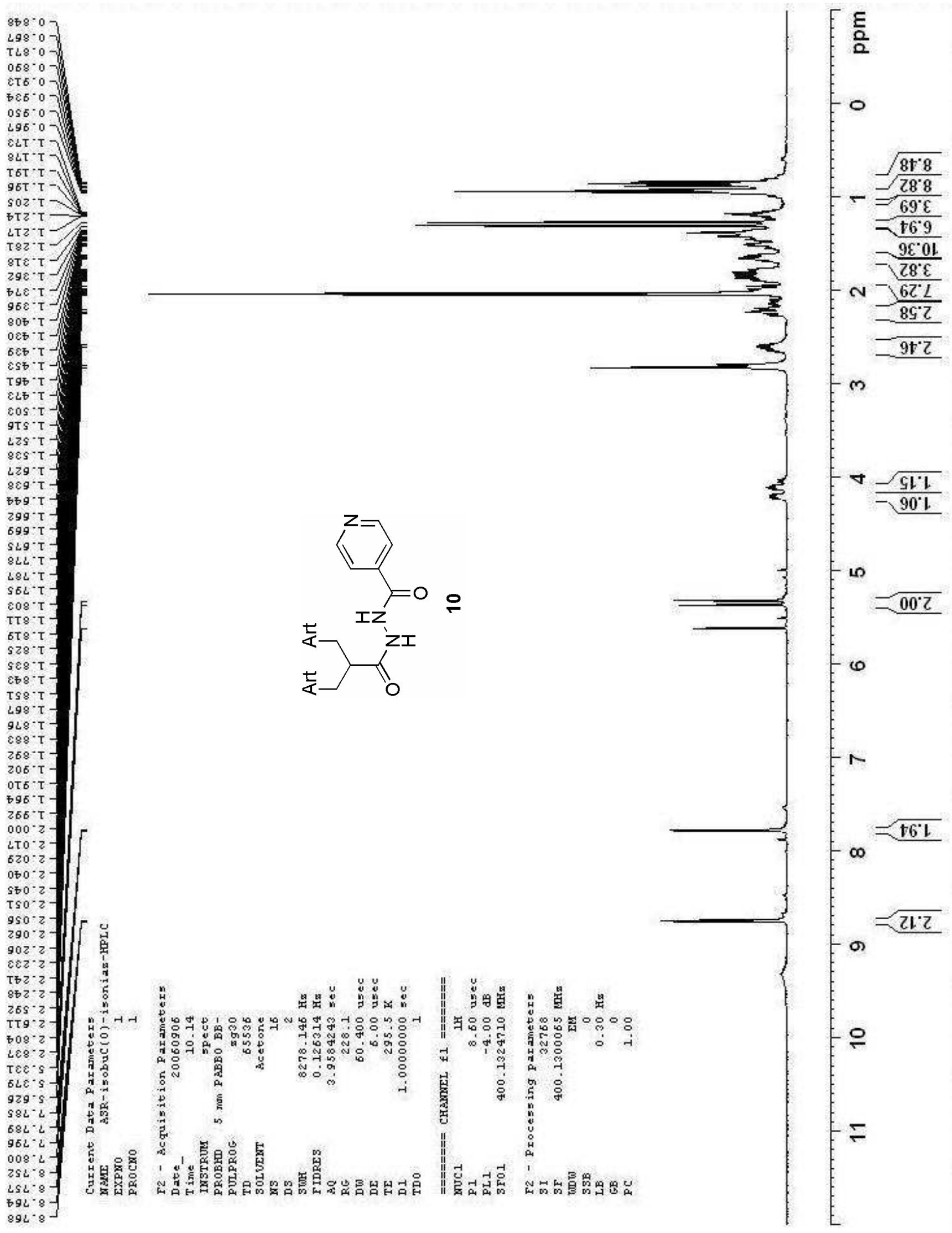



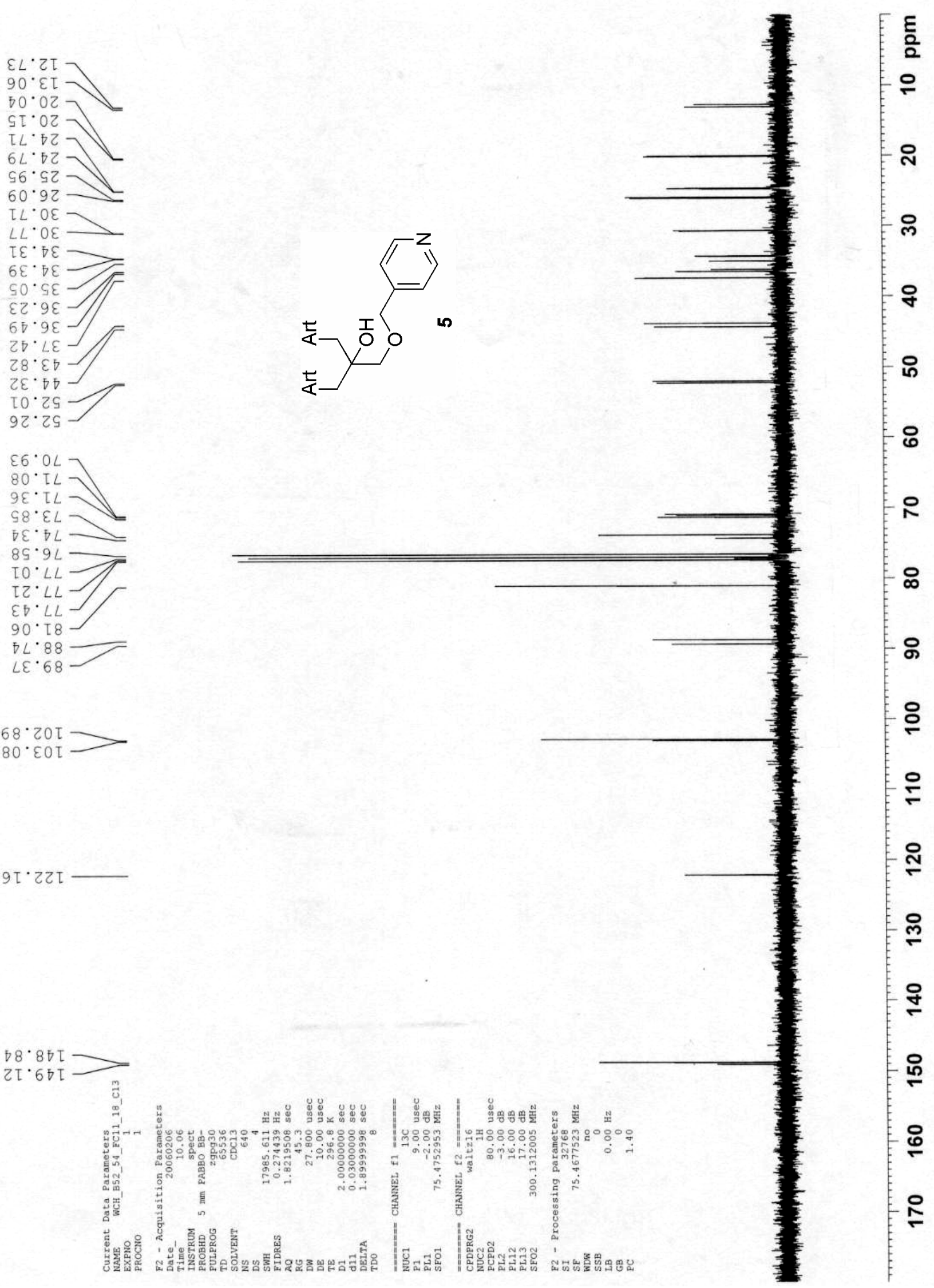

옹

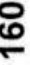

$\stackrel{9}{=}$ 

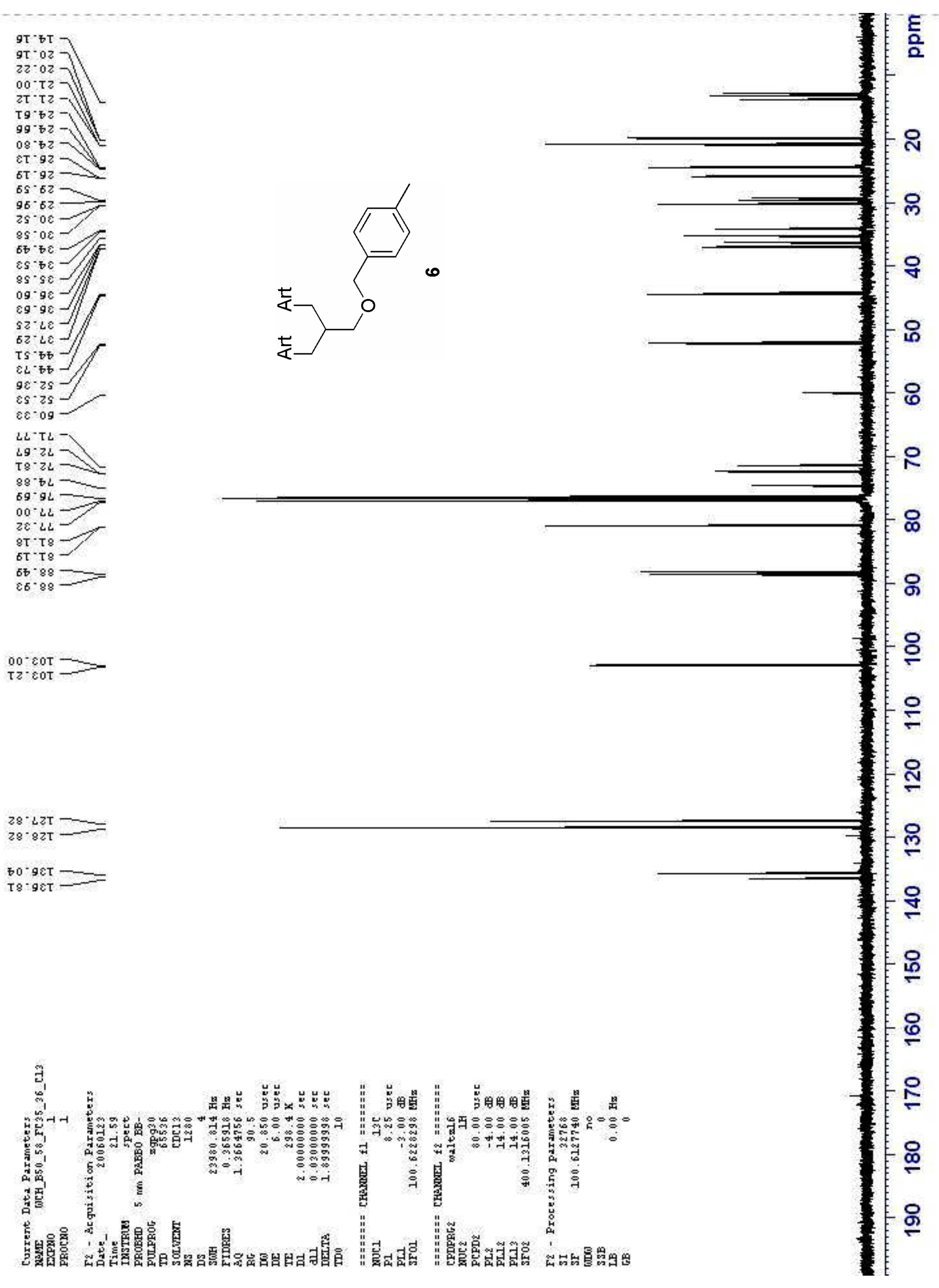

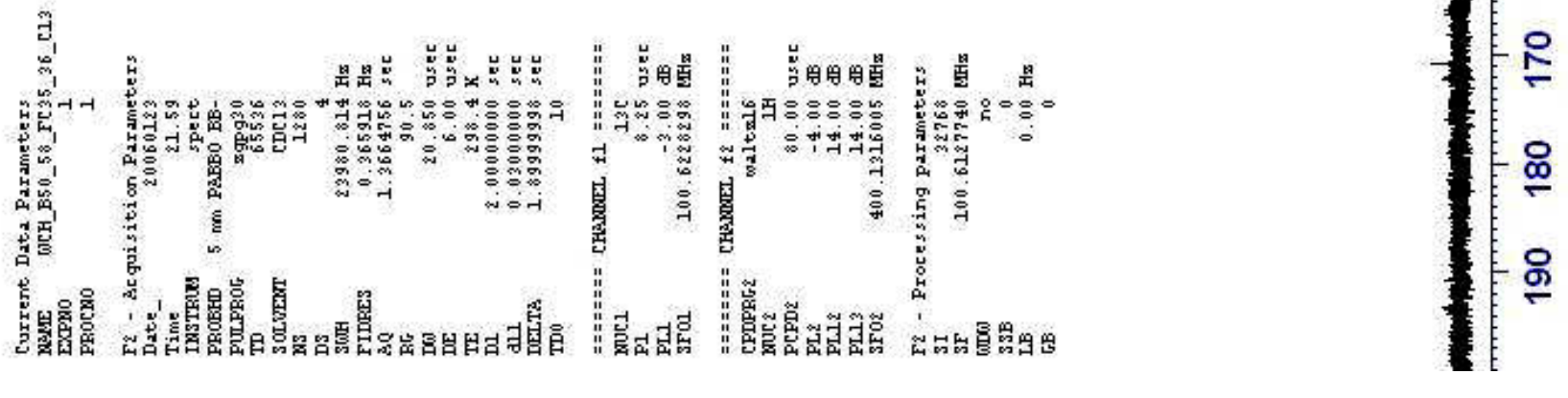



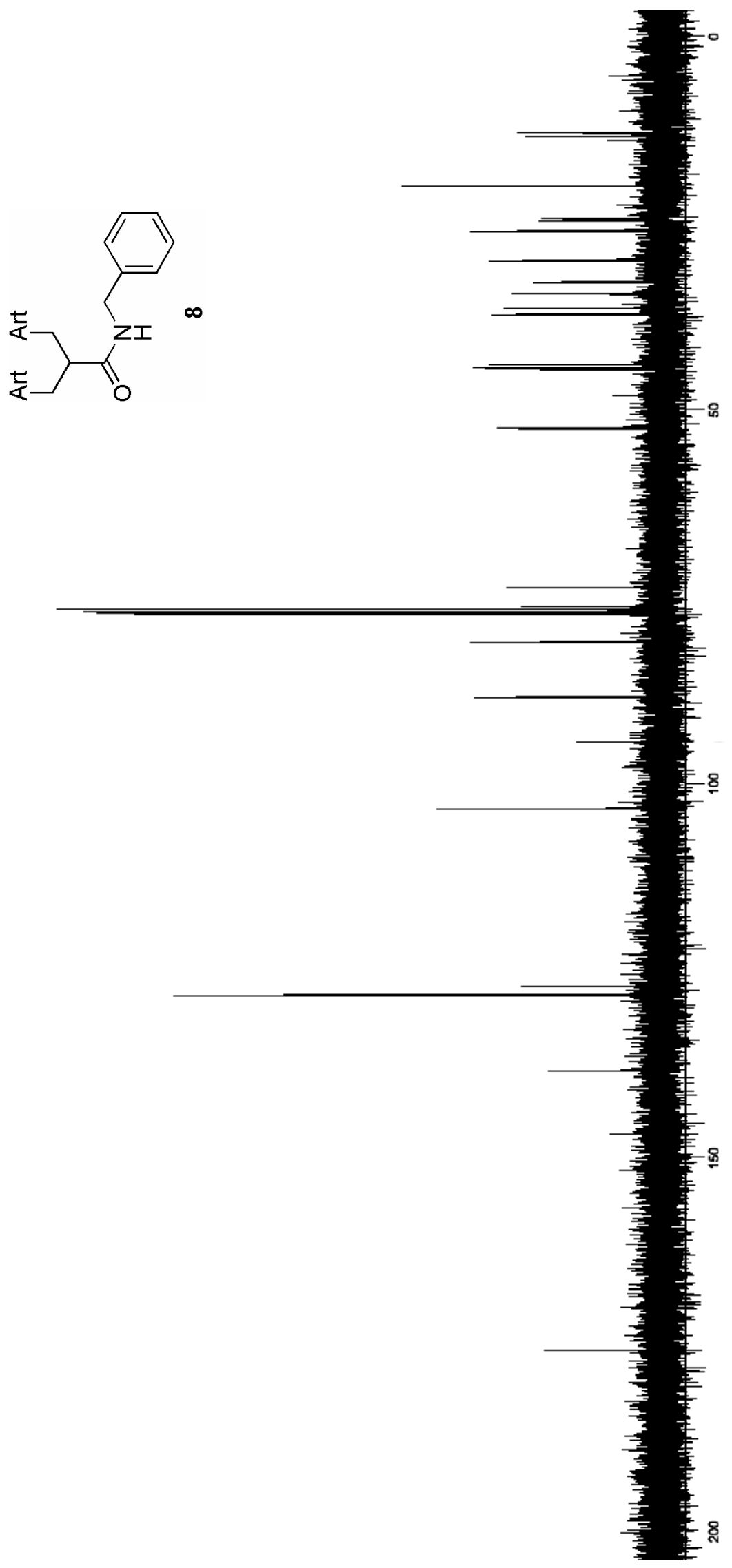

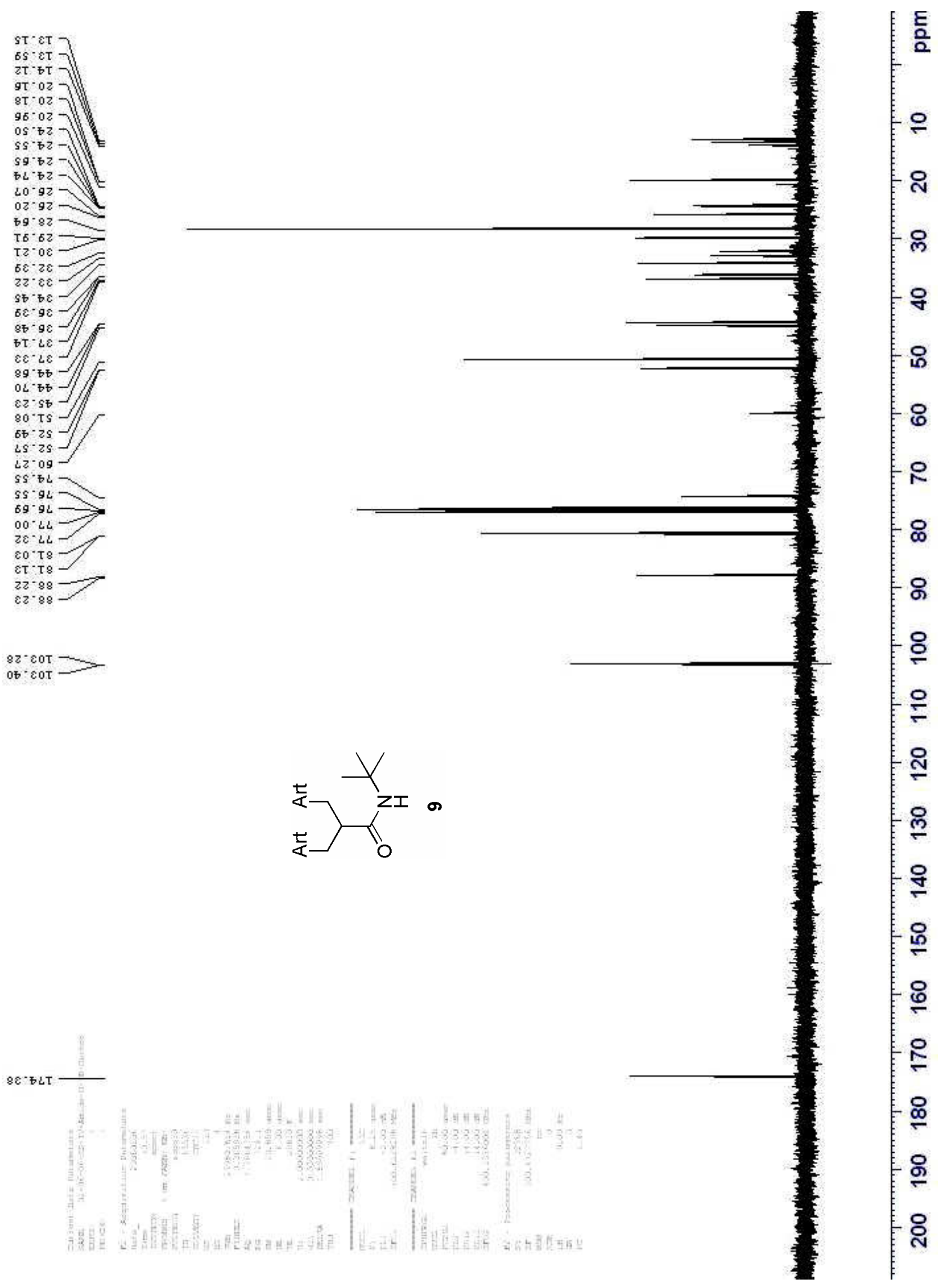

$82^{\circ} \cdot 0 \mathrm{TT} \longrightarrow-$
$0 \mathrm{~T} \cdot \mathrm{cot} \longrightarrow-$ 

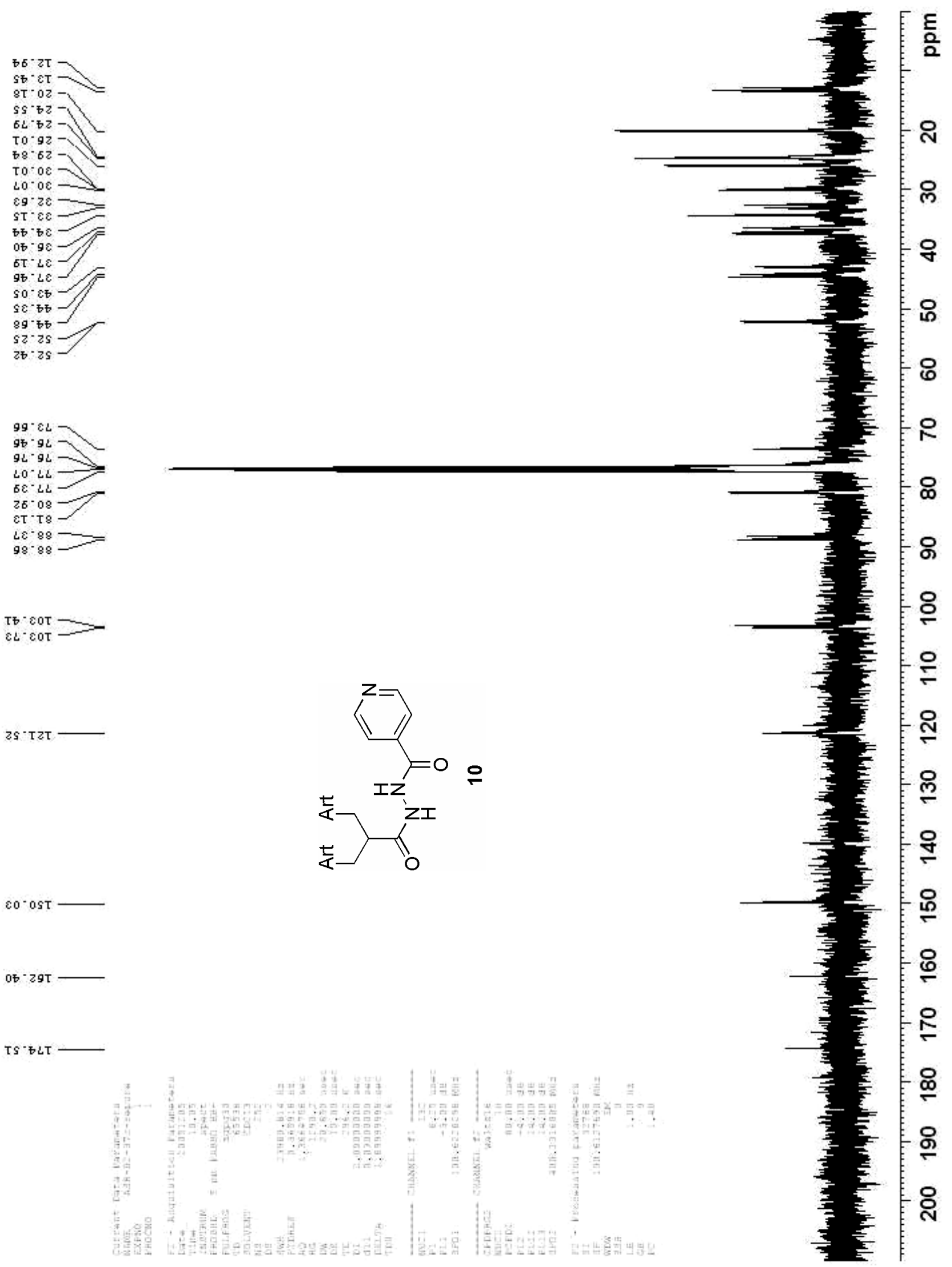


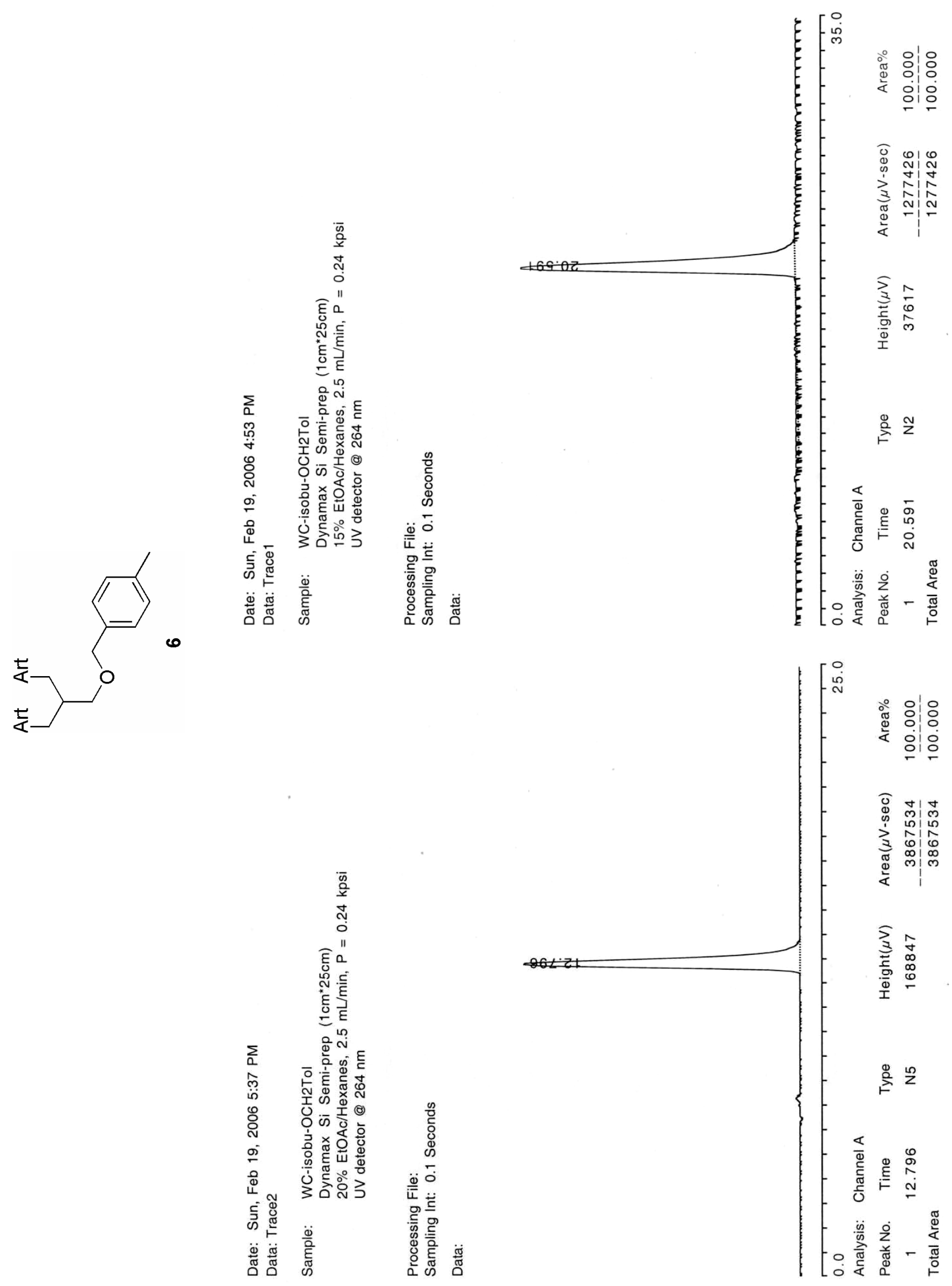




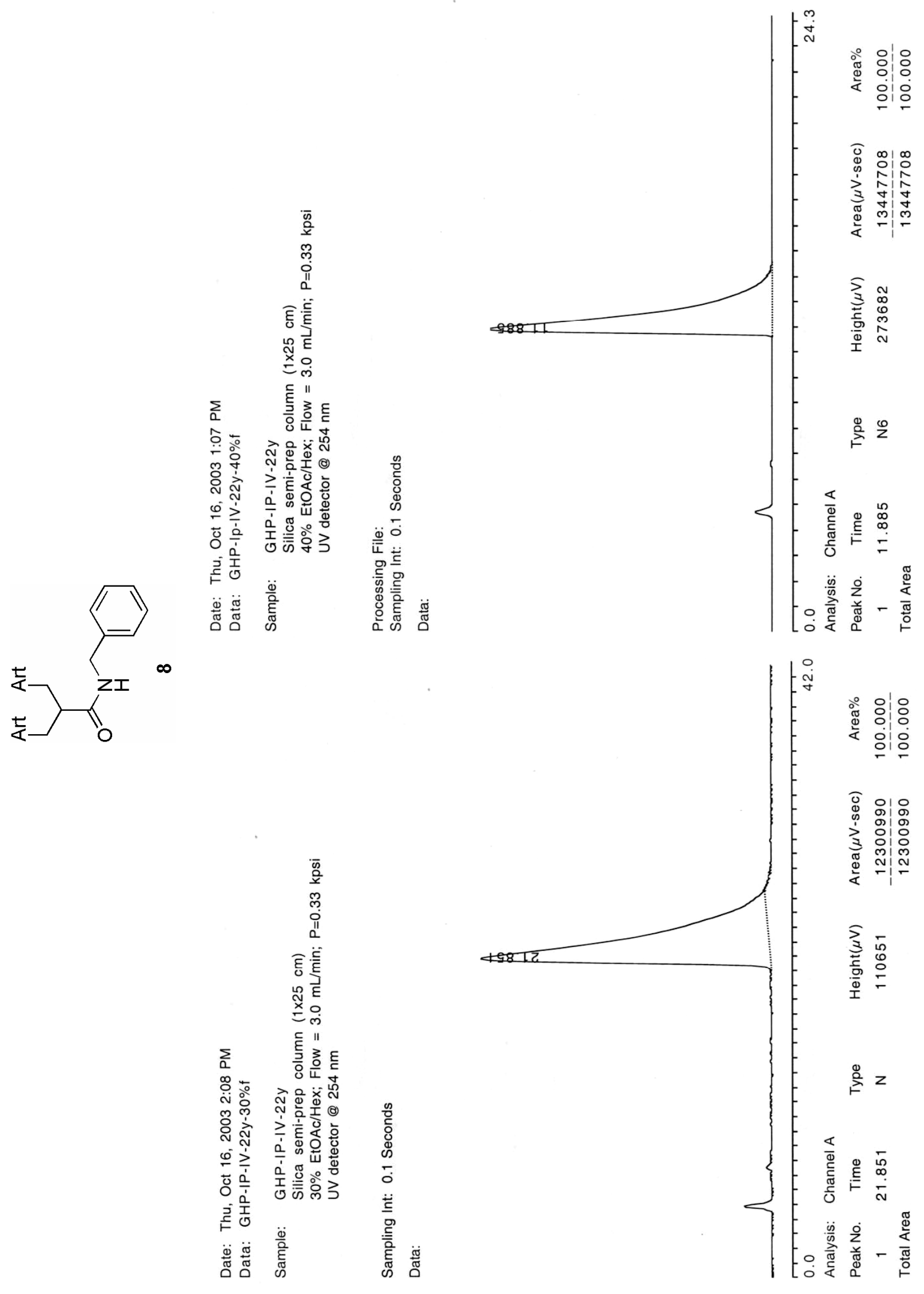




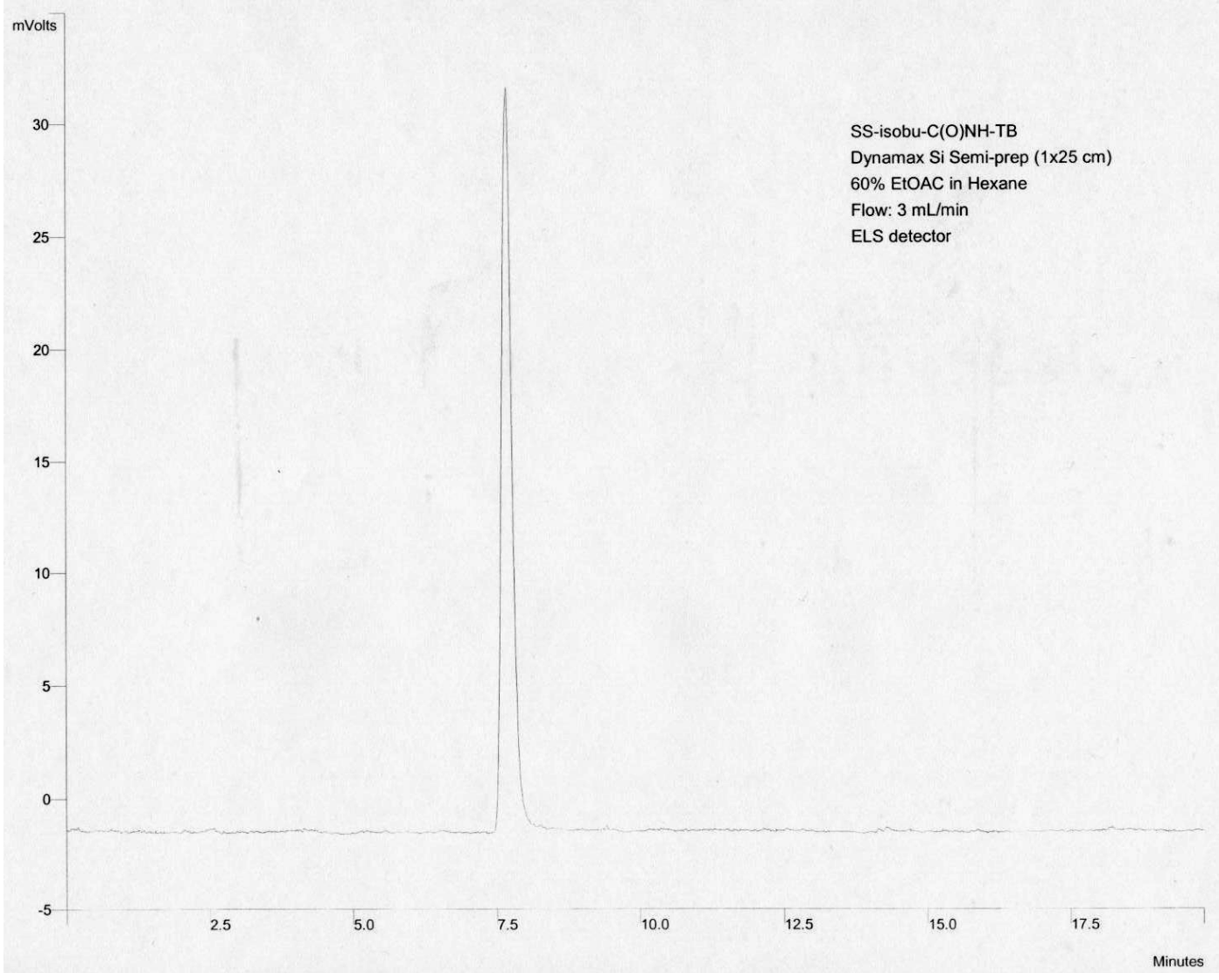

Art Art

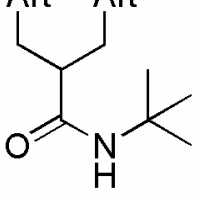

9

mVo

400

SS-isobu-C(O)NH-TB

Dynamax Si Semi-prep (1×25 cm)

$0 \%$ to $60 \%$ EtOAC in Hexane from $t=0$ to $t=20 \mathrm{~min}$

$60 \%$ EtOAC in Hexane from $\mathrm{t}=20$ to $\mathrm{t}=25 \mathrm{~min}$

$60 \%$ to $100 \%$ EtOAC in Hexane from $\mathrm{t}=25$ to $\mathrm{t}=30 \mathrm{~min}$

$100 \%$ EtOAC after $\mathrm{t}=30 \mathrm{~min}$

Flow: $3 \mathrm{~mL} / \mathrm{min}$

ELS detector

200 


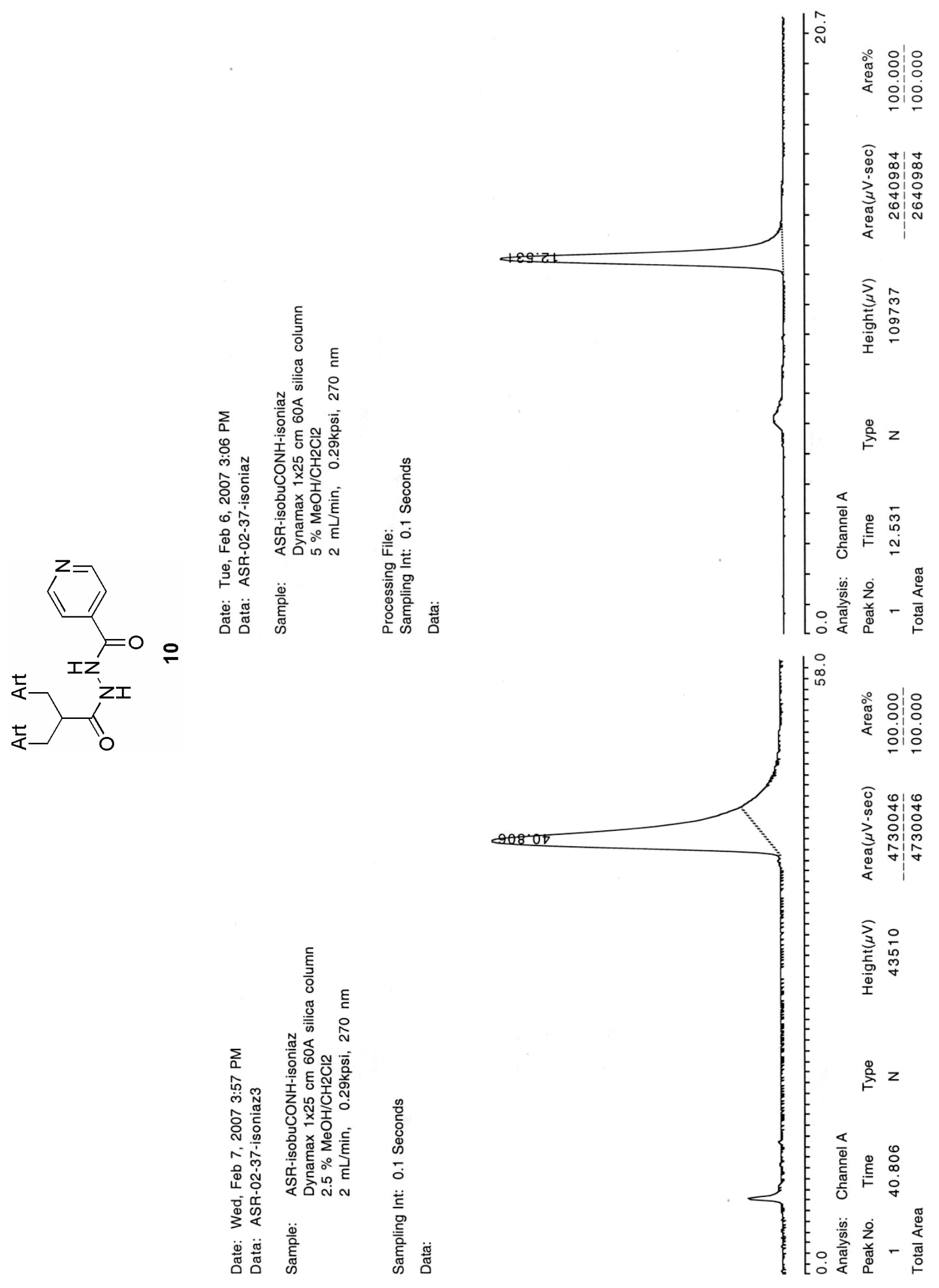

